\title{
Analysis of Aqueducts Subjected to Hydrostatic and Dynamic Loads Using 3D - Solid Modeling
}

\author{
Jitendra Singh Yadav ${ }^{1 *}$, Suhas S Babu²
}

\footnotetext{
1,* Department of Civil Engineering, National Institute of Technology Hamirpur, Hamirpur, India

2 School of Civil and Chemical Engineering, Manipal University Jaipur, Jaipur, India

* Corresponding Author: jitendershine@gmail.com
}

Received: 22-07-2020

Accepted: 07-09-2020

\begin{abstract}
In many areas of developing countries, the access to fresh water is limited even today. Aqueducts are the major structures in water supply and diversion schemes when carrying the water over natural and artificial obstacles such as valleys, rivers, roads, railway lines, canals etc. During an earthquake, the effect of water sloshing on the walls of aqueduct and the resulting hydrodynamic forces is often neglected. In this study, the analysis is carried out for a single span elevated aqueduct using finite element analysis, in which the structure is discretized into smaller elements. The structure is modelled using solid elements in Staad Pro V8i software for different loads. The behavioral response of aqueduct structure subjected to hydrostatic loads and dynamic loads due to seismic ground excitation has been analyzed. It has been observed that the structure is more vulnerable to dynamic loads compared to hydrostatic loads. The effect of dynamic loads due to sloshing of water under seismic forces is predominant. The stresses induced by hydrodynamic loads are observed to be 2.4 times more than hydrostatic loads.
\end{abstract}

Key words: Aqueducts; Tie beams; Hydrostatic and hydrodynamic loads; Solid modelling.

\section{Introduction}

The supply of adequate fresh potable water is one the most important requirements for any community. An aqueduct is a cross drainage structure which is constructed to convey water over an obstacle such as natural streams, valleys etc. Aqueduct is derived from Latin word, (Latin: aqua + ducere, "to lead water") man-made structure for carrying water. In modern engineering, aqueduct refers to a structure used to convey water from its source to its distribution point. Aqueducts have been important particularly for the supply of water to areas with limited direct access to freshwater sources. They form a component of systems that run for very long distances through different terrains from the source to distribution point. They serve as bridge for conveying water and it can also be used for other purposes like Foot Bridge which help people to cross the valley in remote places (Wu et al., 2006).

In addition to the above importance, aqueducts also help in regulating flood by draining away the overflow, they can be used for inland navigation and also for major river diversion schemes which is a serious thought taken up by many countries to supply the water from the areas of abundant water resources to areas of water scarcity. Thus helps in filling of natural lakes and reservoirs, and regenerate the ground water. Thus, the aqueducts which form a major link in irrigation systems are extremely significant structures and needs to be carefully designed. A major earthquake would create serious consequences for the people who are purely dependent on it for water.

Many studies have been undertaken in the past years regarding the seismic design of aqueducts. Aqueducts were designed earlier using bridge design codes. Even now there are no stipulated codes for seismic design of aqueducts. But aqueducts are not same as bridges and the conventional bridge design cannot be applied to the design of aqueducts because it consists of 
large masses of water in it. An earthquake excitation makes the water mass to cause sloshing on the walls of the aqueduct. This creates the hydrodynamic forces on the walls of the aqueduct which is often not accounted for in much design of aqueducts. But later, some of the linear methods were developed to study the water-structure interaction such as Westergard's additional mass method and Housner's model method. Some of the other methods include the non-linear methods to study the water-structure interaction such as boundary element method and ALE (Arbitrary Lagrangian-Eulerian) finite element method which considered the effect of water sloshing (Bai et al., 2011; Gao et al., 2014).

Haroun and Tayel (1985) studied and compared the effect of vertical translation of elastic, cylindrical liquid storage tank under vertical and horizontal seismic excitation for three different support conditions of the wall, namely, fixed, simply supported and partly fixed conditions. From the results, it was found that the maximum wall displacement and the maximum wall stresses in case of variable wall thickness were nearly two thirds of tanks with uniform wall thickness. Axial stresses induced in an anchored tank due to the vertical component of earthquake excitation were found to be much smaller than those due to the horizontal components. Li et al., (2003) studied the vertical seismic response for a large-scale beam-supported aqueduct. It was observed that the frequencies of aqueduct when it was full were lower than that when it was empty condition due to participating water-mass but the mode shapes in both the cases were identical. For the different seismic inputs, the structural responses of the aqueduct increased with the depth of water in aqueduct. From the results, it was shown that the vertical seismic effects on the aqueduct structure were not small. So, the effects of vertical seismic excitations on the aqueduct should be considered in the structural designs.

Chen and Hao (2004) studied the water-structure interaction and the effects of bearing properties on its responses to seismic ground excitation. It was observed that using isolated bearings in the design can significantly reduce the aqueduct responses compared to the hinge support. When the aqueduct is hinge supported, the stress induced by water vibration is negligible compared to that of aqueduct when a 1:20 scaled aqueduct model with hinge support was tested on shaking table. This study also demonstrated that using rubber bearings to isolate the aqueduct from the piers would greatly reduce aqueduct responses to seismic ground motion as compared to using hinge supports. Wu et al., (2006) studied the response of threedimensional high frame supported U-shaped aqueduct under seismic excitation resulting large amplitude sloshing effects of water and effects on the aqueduct structure. It was observed that under strong earthquake actions, the effects of sloshing are significant. The external excitations were found responsible to induce large water sloshing effects that significantly changed the distribution of hydrodynamic pressures and stresses in the aqueduct. The results showed that when the earthquake action reached a peak, the amplitude of the sloshing water may reach a maximum after several periods of water sloshing.

Mitra and Sinhamahapatra, (2007) had discussed, the slosh dynamics of a partially filled rigid container during an earthquake excitation. The characteristics of slosh displacement, slosh frequencies, mode shapes, hydrodynamic pressure over the container wall and around the submerged component had been studied. The analysis was carried out considering only small amplitude waves. It was found that the dimensions of submerged structure had very strong effect on the slosh dynamics. It was also observed that the hydrodynamic pressure on the submerged block increased with height of the submerged block but decreased on the walls of tank. The dynamic pressure on the near wall was found to be increased quite considerably as the submerged block moved towards it, while the pressure on the far wall was decreased. Rafiee et al., (2008) had presented the "Non-Smooth Contact Dynamics" (NSCD) computational method, of rigid or deformable discrete elements for dynamic simulation to analyze the structural behavior and stability of antique structures during an earthquake vibration. The "Nîmes arena" and "Arles aqueduct" in France using LMGC90 code with 3D rigid element model were studied. The author studied the behavior of masonry structure and the failure modes due to seismic wave 
propagation. The results obtained from the model subjected earthquake vibration showed that the structure was highly vulnerable, especially at the upper level of the outside wall.

Bai et al., (2011) had discussed the dynamic response of large aqueduct for different water depths in the aqueduct using Housner's method. From the result, it was observed that, the dynamic displacements and dynamic stresses of aqueduct structure increased with the depth of water in aqueduct. As the water increased, the mass of the upper portion of the aqueduct structure was also found to be increased. From the calculation results, the maximum compressive stress was observed in the bottom middle wall of the downstream end, the maximum tensile stress was observed in the bottom middle wall of the upstream end. Zhang, et al., (2013) studied the water-structure interaction of the aqueduct structure subjected to windinduced vibration for different depths of water. The stability of the structure for natural vibration characteristics, seismic responses, and wind responses for rigid bearings and isolated bearings is compared. The results showed that the use of isolation bearings was able to improve the performance during an earthquake but it reduced the structural stiffness and increased the vibration period by 1.74 times compared to rigid bearings. The stresses of aqueduct with isolated bearing were lesser than those aqueducts without isolated bearing under seismic conditions. However, under the wind load, the stresses were found to be much larger on the aqueduct with isolated bearing compared to aqueducts without isolated bearing.

Zhang et al., (2013) studied the dynamic properties of a U-shaped aqueduct induced by the fluctuating winds for rigid bearings isolated rubber bearings. It was observed that the isolated rubber bearings were helpful in improving the earthquake resistance capacity but they reduced the structural stiffness, increased the structural vibration period and reduced the wind resistance performance of aqueduct structures. It was observed that the hydrodynamic pressure and the overturning force on the wall increased with the depth of water in the aqueduct. The values with rubber bearings were found to be greater than the ones with rigid bearings by 4$7 \%$. The maximum average overturning moment of aqueduct with rubber bearings were approximately 9 times larger than the one with rigid bearings for identical water depth. It was found that the isolated rubber bearings produced maximum stresses and overturning forces which reduced the structural stability for wind resistance of aqueducts. Gao et al., (2014) had discussed about the beam-type aqueduct 2.5D FSI (fluid-structure interaction) model to analyze the aqueduct-water coupling system and compared it with typical 3D FSI model in the numerical results. A 3D FSI model and three 2.5D FSI models with different amount of 2D FSI planes were presented in the static and dynamic analyses of the aqueduct. In this model, the beam-type aqueduct body was divided into a number of substructures and meshed by 3D solid elements. In the study, there were three kinds of 2.5D FSI models with 5, 8 and 10 2D FSI planes respectively. The results showed that the 2.5D FSI model with 8 2D FSI planes of 2D FSI planes to had good simulation results for dynamic and static analysis of beam-type aqueduct. It was also shown that the computing time of the 2.5D FSI model is about 4 hours, while the 3D FSI model costs about 7 hours. It was obvious that the 2.5D FSI model greatly reduces the computing time cost on the premise of satisfying requirements of calculation accuracy.

From the review of past literature, it is found that the combined effect of aqueduct with and without tie beams subjected to the hydrostatic and hydrodynamic forces has not been studied in detail. The finite element method of modelling of an elevated aqueduct using Solid Elements in Staad Pro V8i software has not been carried out. The effects of water sloshing on the walls of the aqueduct induced due to combined effect of horizontal and vertical earthquake forces has not been studied. The aim of this work is to study the structural response of aqueduct subjected to static and dynamic loading.

\section{Design Philosophies}

The methods available for studying water-structure interaction and for calculation of hydrodynamic pressure are: 
1) Westergard's additional mass method

2) Housner's model method

\subsection{Westergaard's Additional Mass Method}

This method was basically developed by Prof. H.M Wastergaard to study the hydrodynamic pressure on dams. In this method, the water is treated as an additional mass. According to Westergaard's theory, the parabolic hydrodynamic pressure exerted on the vertical face of dam structure on the upstream was determined to be the same as that pressure exerted by water on the wall of dam. This water is treated as "additional mass" which moved with the dam during an earthquake ground motion. Prof. Westergaard developed equations for these individual masses exerted over the height of dam as a result of horizontal earthquake acceleration (Jain and Jaiswal, 2007).

The equation for the individual masses is given as:

$$
m(z)=\frac{7 w}{8 g} \sqrt{H^{*} z}
$$

where, $w=$ unit weight of water

$\mathrm{g}=$ acceleration of gravity

$\mathrm{H}=$ depth of reservoir water

$\mathrm{z}=$ depth of water from surface

In this approach, the structure (dam) is treated as rigid, semi-infinite and have vertical upstream surface. Surface waves in fluid are neglected. The distribution of hydrodynamic pressure occurred along upstream surface after earthquake takes into account as mass distribution pulsed with the dam. Individual masses calculated with distribution of hydrodynamic pressure are added on the nodes of the finite element mesh along upstream surface of the dam. The water is treated as a compressive non-cohesive fluid body (Jain and Jaiswal, 2007).

\subsection{Housner's Method}

Housner's proposed simple methods to evaluate the influence of dynamic fluid on the rigid rectangular tank subjected to earthquake forces.When the water tank is subjected to earthquake excitation, it causes the sloshing of water. This sloshing of water on the structure will induce the generation of hydrodynamic forces. This is idealized as two components called impulsive and convective masses of water. The impulsive mass of water is assumed as fixed mass which is rigidly connected to the tank and convective mass of water is assumed to be connected with flexible springs to the tank wall to simulate the effects of sloshing motion of water (Jain and Jaiswal, 2007).

The impulsive pressure of water mass on wall of tank is shown in Fig. 1(a) and Fig. 1(b). In Fig. 1(a) hi represents the height where the resultant of impulsive hydrodynamic pressure acts on wall from the bottom of tank. Whereas hi* represents the height where the resultant of impulsive hydrodynamic pressure acts on the wall and base is located from the bottom of tank wall (Fig. 1(b)). Thus, if influence of base pressure is not calculated, impulsive mass of liquid, mi will act at a height of hi and if effect of base pressure is well-thought-out, mi will act at hi*. Similarly, Fig. 2(a) and Fig. 2(b) show the height where the resultant of convective pressure act on the wall represented by hc, while, hc* is the height at which resultant of convective pressure on wall and base is located (Jain and Jaiswal, 2007). 

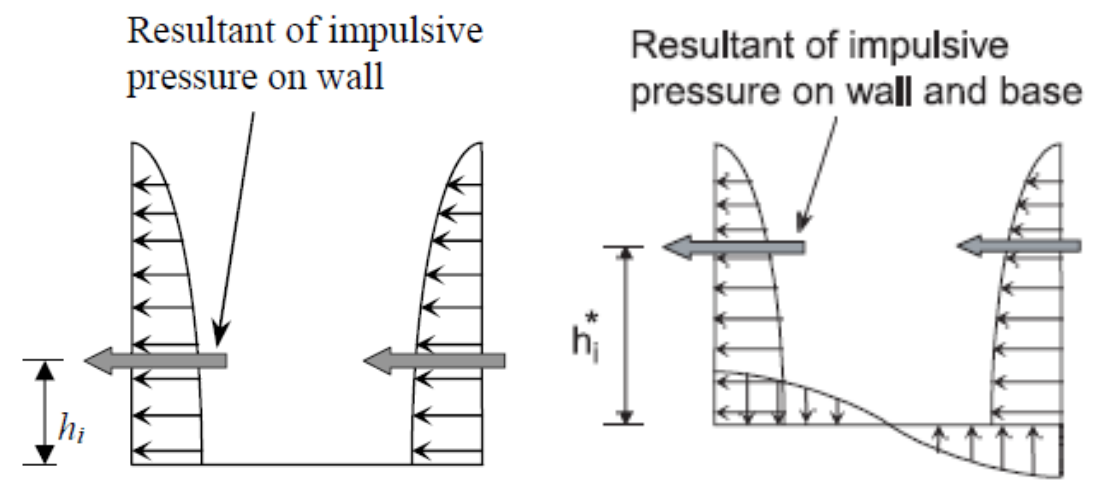

Fig 1. (a) Impulsive pressure on wall (b) Impulsive pressure on wall \& base
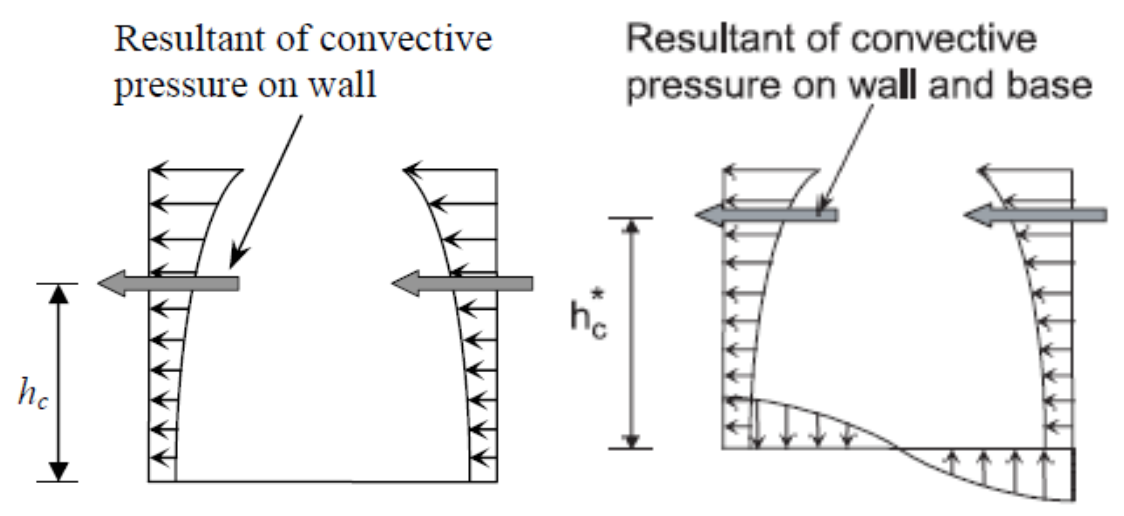

Fig 2. (a) Convective pressure on wall (b) Convective pressure on wall \& base

\subsection{Hydrodynamic Pressure}

The main purpose of the aqueduct is conveying water, but because of insufficient researches on the dynamic response of aqueduct structures, the aqueducts are studied and analyzed for their seismic performance only and not hydrodynamic loads. Though the aqueducts are considered as bridges for carrying water over obstacles, the dynamic responses of an aqueduct structure are very dissimilar from those of a vehicular bridge. The large mass of water sustained by an aqueduct is far larger than the loads taken by a bridge. These loads on the aqueducts are more pronounced during an earthquake. The liquid motion will cause the sloshing on the base and walls of the structure and significantly induces the hydrodynamic pressure on the aqueduct structure.

Due to earthquake ground motion, both tank and the liquid are subjected to horizontal acceleration. Both the horizontal and vertical earthquake excitation induces the water sloshing and the hydrodynamic loads on the structure. But it is due to the horizontal earthquake acceleration, the effects are more pronounced compared to that due to the vertical ground excitation (Li et al., 2003).

At the lower region of tank liquid acts like rigid mass and it is called as impulsive liquid mass. This impulsive mass creates hydrodynamic pressure on the side and base of tank. The sloshing motion of water can be seen in the upper region of tank and it is called as convective liquid mass. The convective mass exerts convective hydrodynamic pressure on side and base of tank. During vibrations, the liquid exerts both impulsive and convective hydrodynamic pressure on side and base of tank along with hydrostatic pressure. The water mass present at the bottom of tank acts like a rigid mass. Whereas sloshing effect is only produced by water present at the top and it acts like a spring-mass model as shown in Fig. 3 (Jain and Jaiswal, 2007; Salamon, 2011). 


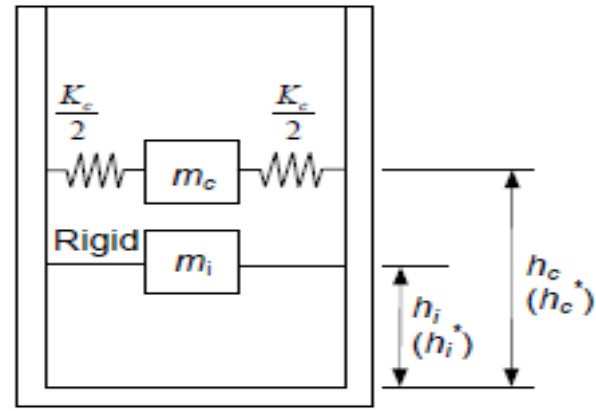

Fig 3. Spring-mass model

\section{Designs}

\subsection{Geometry}

Although in practical situations, the size of aqueduct is decided based upon the actual discharge of water that is required to be pass through the aqueduct. In this study, the structural behavioural response of aqueduct subjected to static and dynamic forces was assessed. An aqueduct of vent size $3.0 \mathrm{~m} \times 3.20 \mathrm{~m}$ and elevated $10 \mathrm{~m}$ above the ground was modelled using 8noded solid elements in Staad Pro V8i software. The geometry of aqueduct is shown in Fig. 4.

The assumed dimensions of the aqueduct to study the behavioural response are as follows:

- $\quad$ Clear vent size of the aqueduct $=3.0 \mathrm{~m}$ wide $\times 3.20 \mathrm{~m}$ deep

- $\quad$ Length of each span $=20 \mathrm{~m}$

- $\quad$ Thickness of floor slab $=400 \mathrm{~mm}$

- $\quad$ Thickness of vertical RC walls $=450 \mathrm{~mm}$

- $\quad$ Number of tie beams $=6$

- $\quad$ Size of tie beams at top $=400 \mathrm{~mm}$ wide $\mathrm{x} 400 \mathrm{~mm}$ deep

- $\quad$ Size of beams supporting floor slab and walls $=400 \mathrm{~mm}$ wide $\times 450 \mathrm{~mm}$ deep

- $\quad$ Spacing of tie beams $=4.0 \mathrm{~m} \mathrm{c} / \mathrm{c}$

- $\quad$ Grade of concrete $=\mathrm{M}-25$

The proposed aqueduct is considered to be elevated $10 \mathrm{~m}$ above the ground, supported on RC piers.

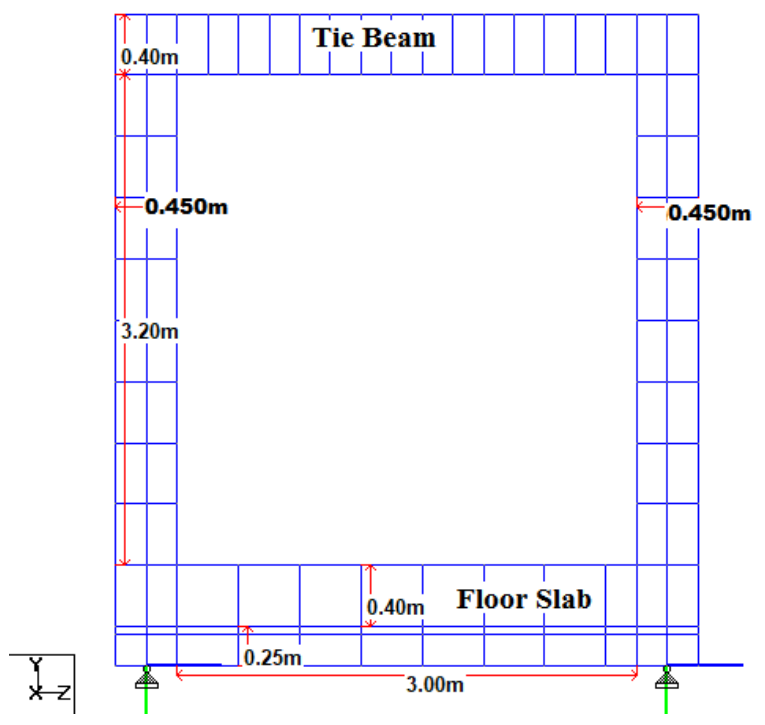

Fig 4. Geometry of aqueduct 


\subsection{Loading}

The aqueduct is assumed to be full of water up to the soffit of top beams. Firstly, the structure is loaded with self-weight, and the hydrostatic water load on floor slab and side walls. Then the earthquake load has been applied by considering the parameters applicable for seismic zone IV as per IS 1893-2016, due to which the water present in the aqueduct is subjected to excitation causing the sloshing of water on the walls of the aqueduct which results in the generation of hydrodynamic forces of water on the structure.

Following loads were considered to be acting on the structure:

1. Dead load.

2. Hydrostatic water load on floor.

3. Hydrostatic water load on side walls.

4. $\quad$ Seismic forces (Zone IV).

5. Hydrodynamic forces.

6. Combination of Self weight and hydrostatic loads

7. Combination of Self weight, hydrostatic loads, seismic force and hydrodynamic forces.

\subsubsection{Static Water Load Calculation}

The static water loads on different elements of the structure has been calculated for the full span of the structure. It has been considered that the water in the aqueduct is filled up to the soffit of top tie beam and accordingly the load on the floor and side walls have been calculated.

\section{Preliminary data:}

Total depth of flow $=3.20 \mathrm{~m}$

Depth of each solid $=0.40 \mathrm{~m}$

Total number of rows of solids $=8$ No's

Density of water $(\gamma)=10 \mathrm{kN} / \mathrm{m}^{3}$

Distribution of water pressure on vertical side walls

Varying load (water pressure) from top to bottom $=\gamma^{*} \mathrm{H}=32 \mathrm{kN} / \mathrm{m}^{2}$ where, $\gamma=$ Density of water $\left(\mathrm{kN} / \mathrm{m}^{2}\right)$

$\mathrm{H}=$ Height of water $(\mathrm{m})$

Load distributions for different depths of water are given in Table 1.

Table 1. Hydrostatic loads applied on the walls of the aqueduct

\begin{tabular}{cc}
\hline Height (h) in 'm' & Load $\left(\mathbf{k N} / \mathbf{m}^{\mathbf{2}}\right)$ \\
\hline \hline 0 & 0 \\
0.40 & 4 \\
0.80 & 8 \\
1.20 & 12 \\
1.60 & 16 \\
2.00 & 20 \\
2.40 & 24 \\
2.80 & 28 \\
3.20 & 32 \\
\hline
\end{tabular}

\section{Calculation of water pressure on floor slab}

Height of water flow $=3.20 \mathrm{~m}$ 
Total pressure on floor slab $=32.00 \mathrm{kN} / \mathrm{m}^{2}$.

\subsubsection{Hydrodynamic Pressure Calculation}

The designs for the calculations of the hydrodynamic pressure resulting from the seismic forces considering the impulsive and the convective masses of water on the aqueduct is carried out. The distributions of hydrodynamic pressure applied on the walls of aqueduct are shown in Table 2.

\subsection{Loading}

Under normal serviceability conditions, the structure should be able to safely carry the static load. At times, when an earthquake load is combined along with the normal operating conditions, the resulting effects of water sloshing on the structure will generate hydrodynamic loads. The structure will be subjected to the dynamic loads along with the hydrostatic loads. These different loading is visualized in different load combinations and is applied on the structure to study its behaviour.

-Load combination 1 (LC1) = DL + Hydrostatic Water Load

-Load combination 2 (LC2) = DL + Hydrostatic Water Load + Seismic 'Z' + Hydrodynamic Load

Table 2. Dynamic loads applied on the walls of the aqueduct

\begin{tabular}{cc}
\hline Height (h) in 'm' & Hydrodynamic Pressure $(\mathbf{P})\left(\mathbf{k N} / \mathbf{m}^{2}\right)$ \\
\hline \hline 0 & 0.000 \\
0.40 & 1.193 \\
0.80 & 4.774 \\
1.20 & 10.741 \\
1.60 & 19.096 \\
2.00 & 29.837 \\
2.40 & 42.965 \\
2.80 & 58.481 \\
3.20 & 76.383 \\
\hline
\end{tabular}

\subsection{Seismic Design Parameters}

The proposed structure is considered to be in seismic zone IV. Therefore, the seismic parameters for calculation of seismic force has been taken according to IS 1893-2016.

- Seismic zone = Zone IV

- Response reduction factor $=5$

- Importance factor $=1.5$

\subsection{Modelling Using Solid Elements}

The structure has been modelled using 8-noded solid elements in Staad Pro V8i software and analyzed for the above specified loads and their load combinations in Finite element method. A continuous complex problem is divided into separate entities referred as finite elements, connected together at a number of nodes. Finite element method (FEM) is most preferable 
method for the analysis of simple and complex problems with minimal errors and higher accuracy.

The support conditions of the aqueduct structure is considered as fixed at one end and the other end is fixed in ' $\mathrm{Y}$ ' and ' $\mathrm{Z}$ ' directions but released in ' $\mathrm{X}$ ' direction to make provision for translational movement within the allowable limits and avoid high negative moments at the ends due to the axial forces in the structure. The 3D model of the proposed structure is represented in Fig. 5(a) and Fig. 5(b).Further, to investigate the importance of tie beams at the top, following cases were modelled and compared to observe the deflection behaviour and stress diagram of the structure under hydrostatic load and also the effect on the bottom beams supporting the floor slab,

The different cases which were considered for the analysis are as follows:

- Without tie beam at the top.

- With tie beam at the top.

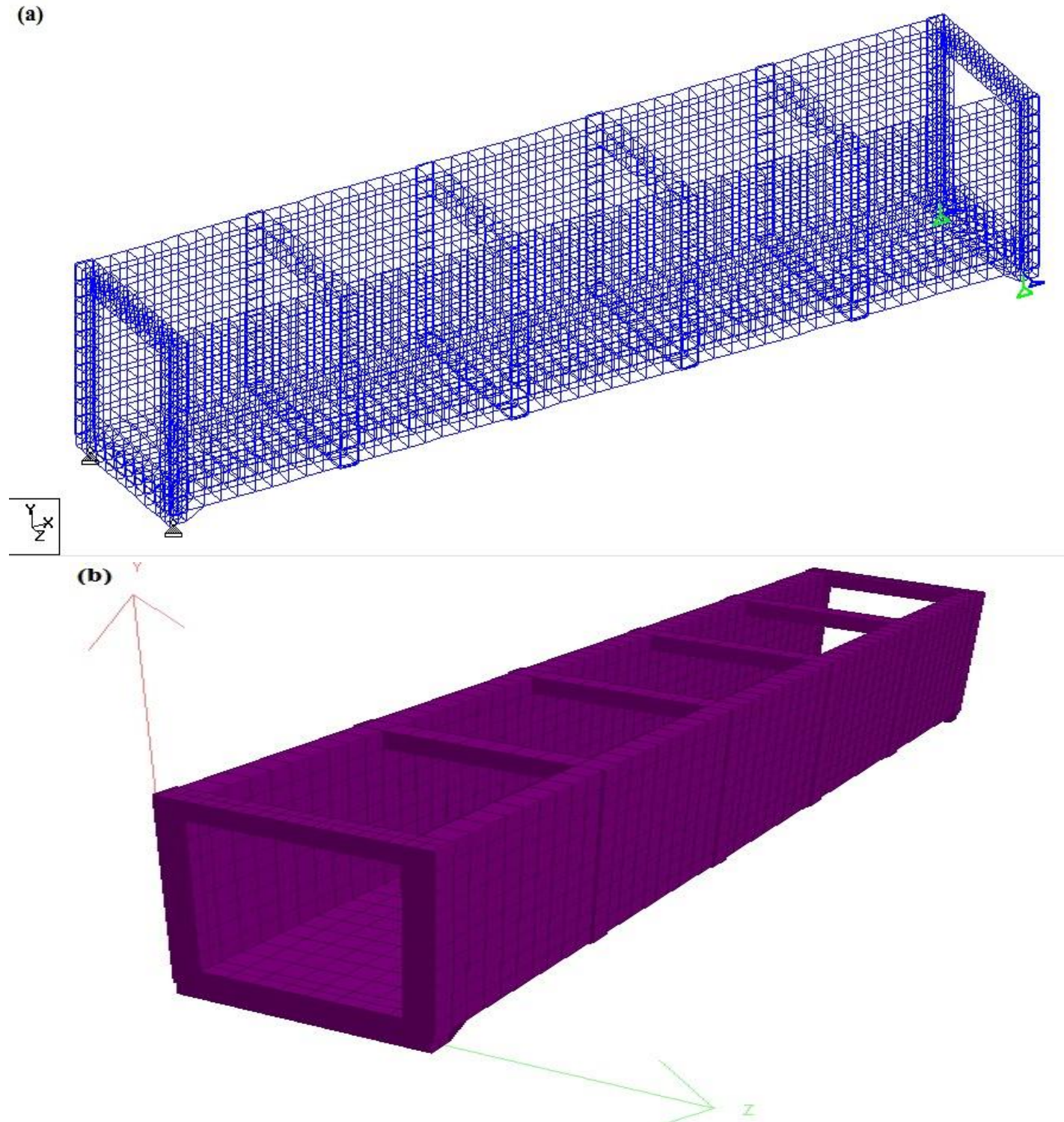

Fig 5. (a) 3D model of aqueduct (b) 3D model of aqueduct 


\section{Results and Discussion}

\subsection{Analysis of Aqueduct without Tie Beams}

Fig. 6(a) shows the 3D view of aqueduct without tie beam. The structure is modelled without tie beams at the top to study the response. The floor slab has not been modelled in this and the loads coming on the floor slab has been calculated and applied on the adjacent beams to study the response of bottom beams. The aqueduct was undergoing excessive deflection beyond permissible limits for static loads itself as shown in Fig. 6(b). Hence, the effect of dynamic loads has not been considered.

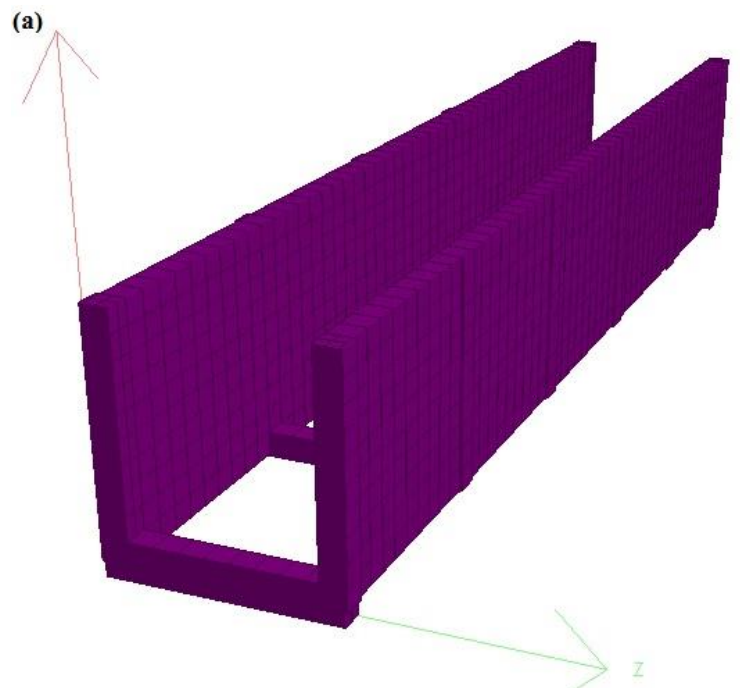

Fig 6. (a) 3D view of Aqueduct without tie beams

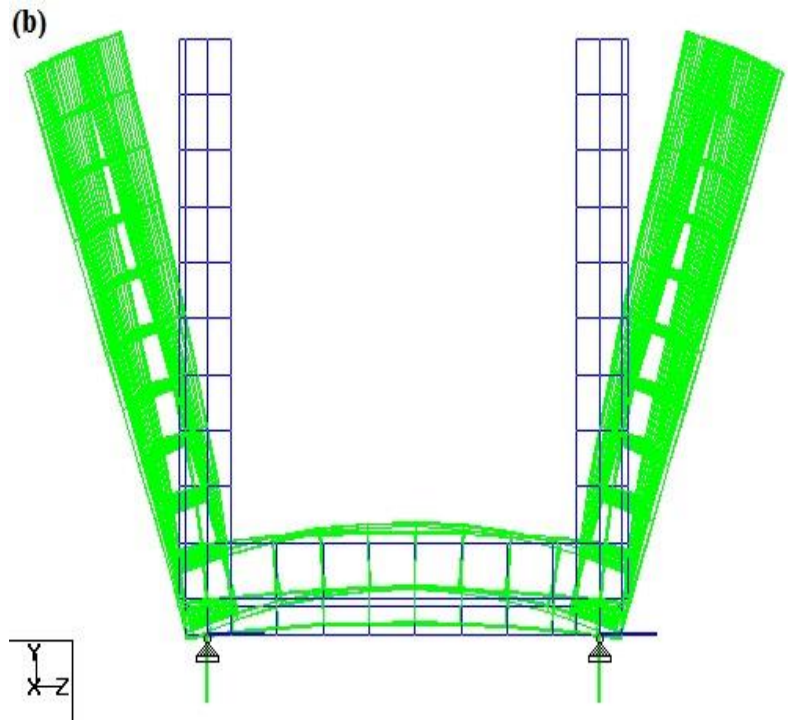

Fig 6. (b) Deflection and bending behaviour of Aqueduct without tie beams

Table 3. Maximum displacements of Aqueduct without and with tie beams

\begin{tabular}{lcccc}
\hline & \multicolumn{2}{c}{ Displacement (mm) } & \multirow{2}{*}{ Resultant } \\
\cline { 2 - 5 } Direction & $\mathbf{X}$ & Y & Z & 27.552 \\
\hline Without tie beams & 2.360 & 5.010 & 27.120 & 4.029 \\
With tie beams & 2.436 & 3.753 & 0.644 & \\
\hline
\end{tabular}


From Table 3, it was observed from the deflection and bending behaviour of the structure that, in the absence of tie beams at the top of aqueduct, the lateral bending of aqueduct structure was predominant and in fact more than the vertical bending due to hydrostatic loads and self-weight. The displacement of the structure in the absence of tie beams at the top was almost 7 times greater than the structure with tie beams at top. As a result, the bottom tie beams are subjected to negative bending moment and the walls were found to be deflecting apart due to lateral hydrostatic forces.

From Fig. 7, it was also observed that the bottom tie beams were subjected to maximum tensile stresses at the top face which resulted in failure of beams. The floor slab also will undergo excessive bending ultimately leading to the failure of structure. Thus, the tie beams at top prove to be a necessary element for the overall performance of the large aqueduct structure.

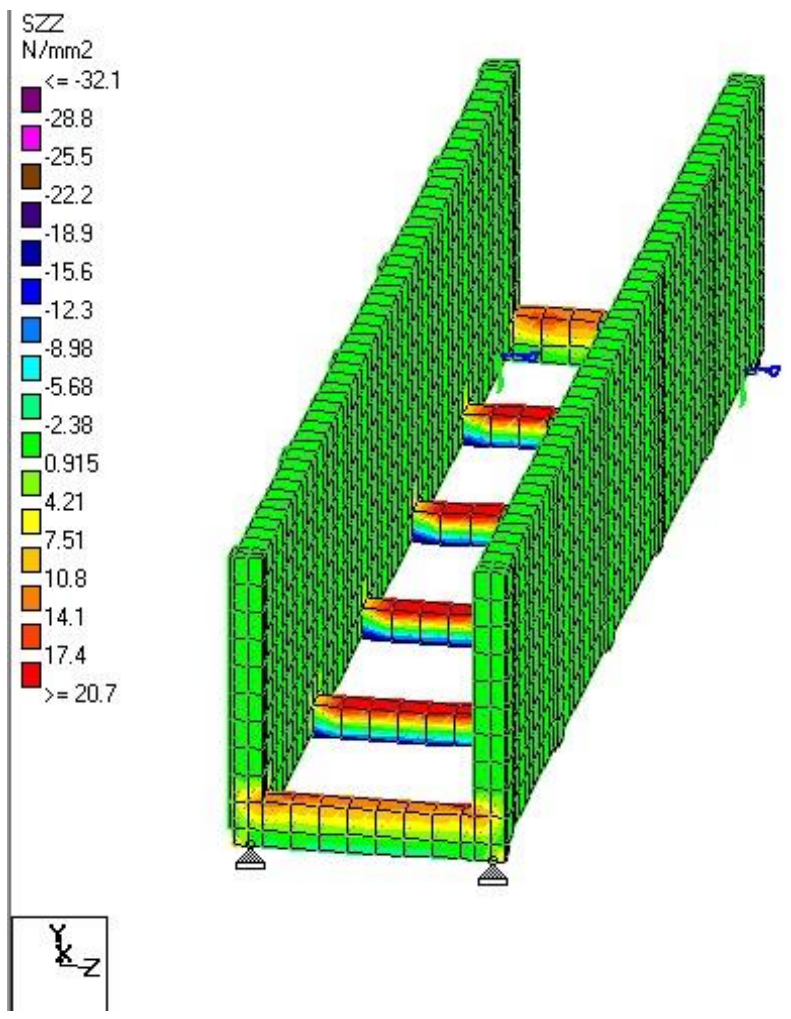

Fig 7. Stresses in the components of Aqueduct without tie beams

\subsection{Analysis of Aqueduct without Tie Beams}

Fig. 8 shows the 3D view of aqueduct with tie beam. The structure is modelled with tie beams at the top and analyzed for static loads to compare with the results obtained for the model without tie beams at the top. The behaviour of the structure is shown in Fig. 9(a) and Fig. 9(b).

From Table 4, it was observed from the deflection and bending behaviour of the structure that, in the absence of tie beams at the top of aqueduct resulted in lateral bending. The provision tie beams helped in reducing the deflection as shown in Fig. 9(b). The values observed for aqueduct with tie beams at the top shows a significant reduction in maximum displacements and maximum stresses on the structure as shown in Fig. 10. From the displacement values, it was observed that the displacement was well within the permissible limits $(10 \mathrm{~mm})$ when the tie beam at top is provided. Fig. 11 shows the comparison of deflection for aqueducts without and with tie beams provided. 


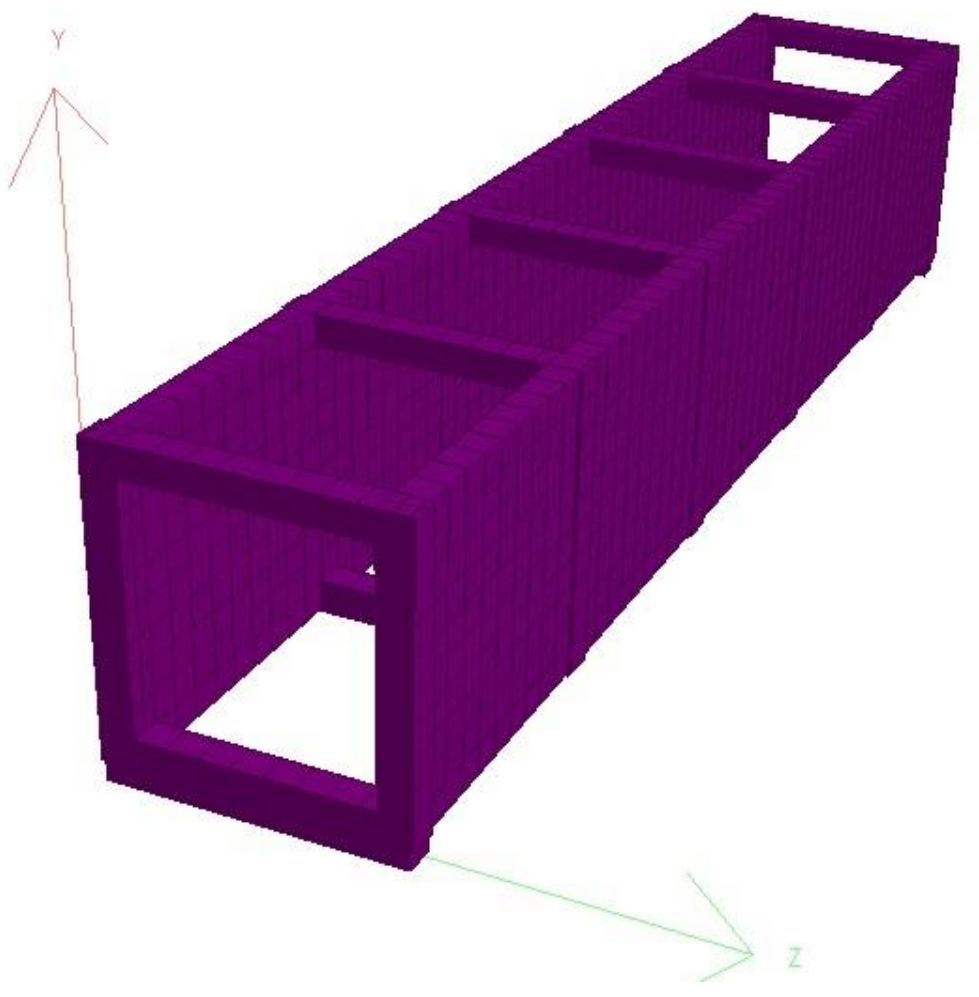

Fig 8. 3D view of Aqueduct with tie beams

Table 4. Maximum stresses of Aqueduct with tie beams

\begin{tabular}{lcccccc}
\hline & \multicolumn{3}{c}{ NORMAL STRESSES } & \multicolumn{3}{c}{ SHEAR STRESSES } \\
\cline { 2 - 6 } DIRECTION & $\mathbf{S}_{\mathbf{X X}}$ & $\mathbf{S}_{\mathbf{Y Y}}$ & $\mathbf{S}_{\mathrm{ZZ}}$ & $\mathbf{S}_{\mathbf{X y}}$ & $\mathbf{S}_{\mathbf{Y Z}}$ & $\boldsymbol{S}_{\mathrm{ZX}}$ \\
$\begin{array}{l}\text { STRESSES } \\
(\mathrm{N} / \mathrm{mm} 2)\end{array}$ & 2.722 & 4.453 & 1.785 & 2.232 & 2.522 & 0.323 \\
\hline
\end{tabular}

(a)

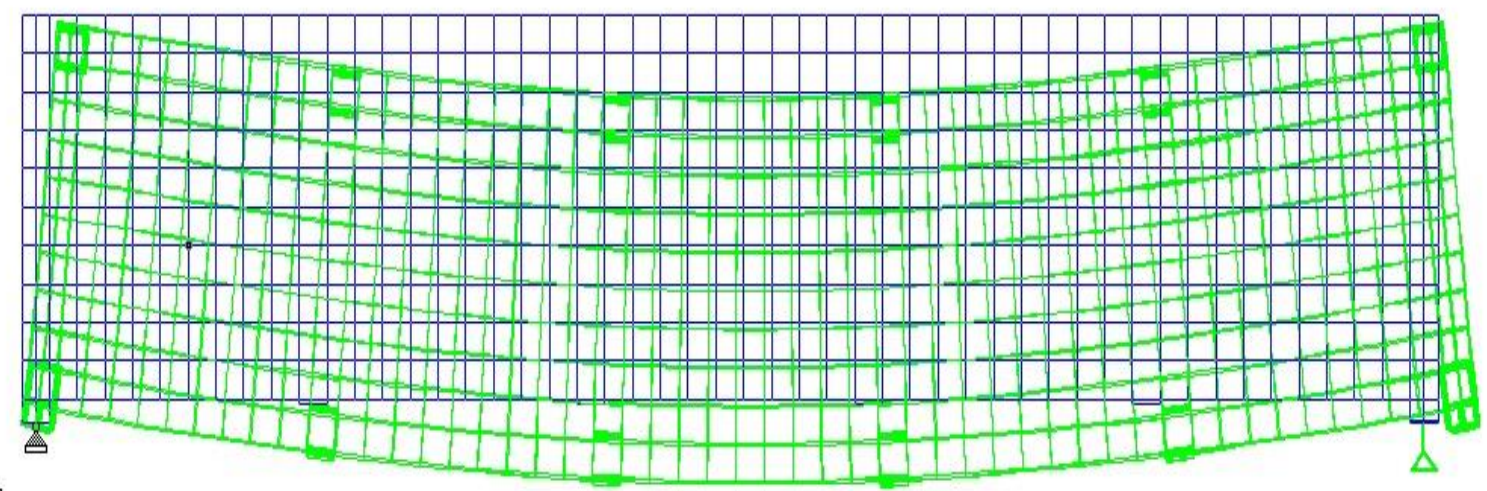

$\overline{Z x}$

Fig 9.(a) Deflection and bending behavior of Aqueduct with tie beams 
(b)

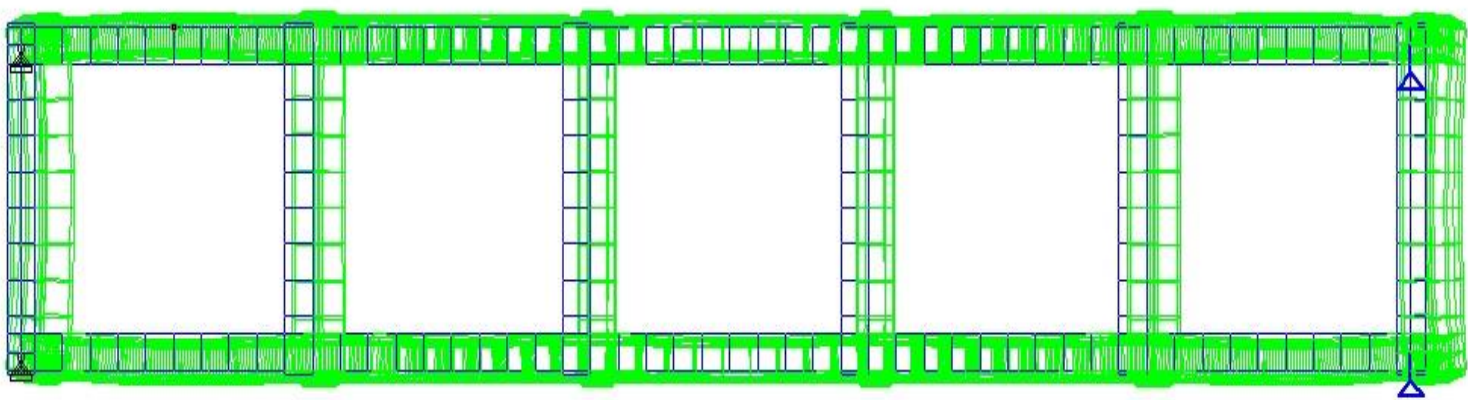

$\rightarrow x$

Fig. 9.(b) Top view of deflection and bending behavior of Aqueduct with tie beams

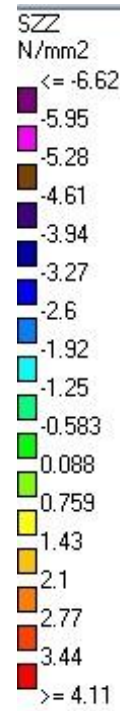

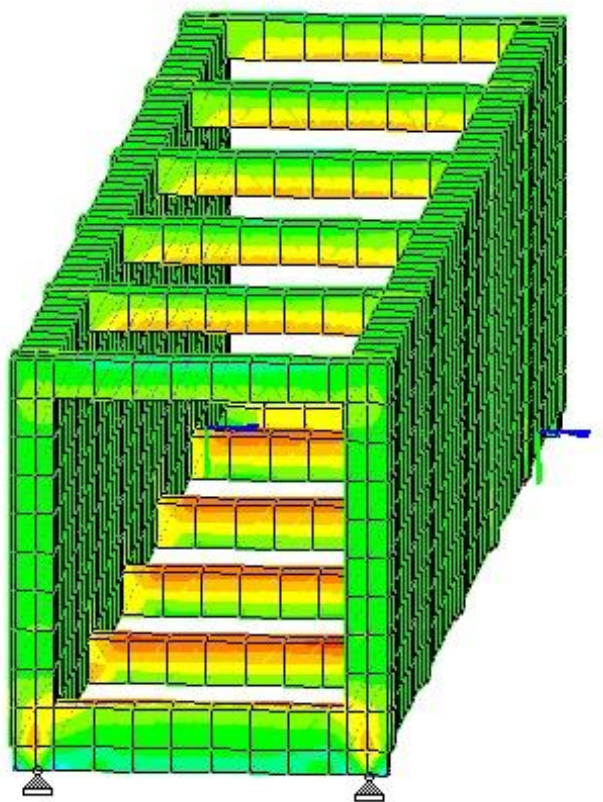

$X_{z}$

Fig.10. Stresses in the components of Aqueduct with tie beams

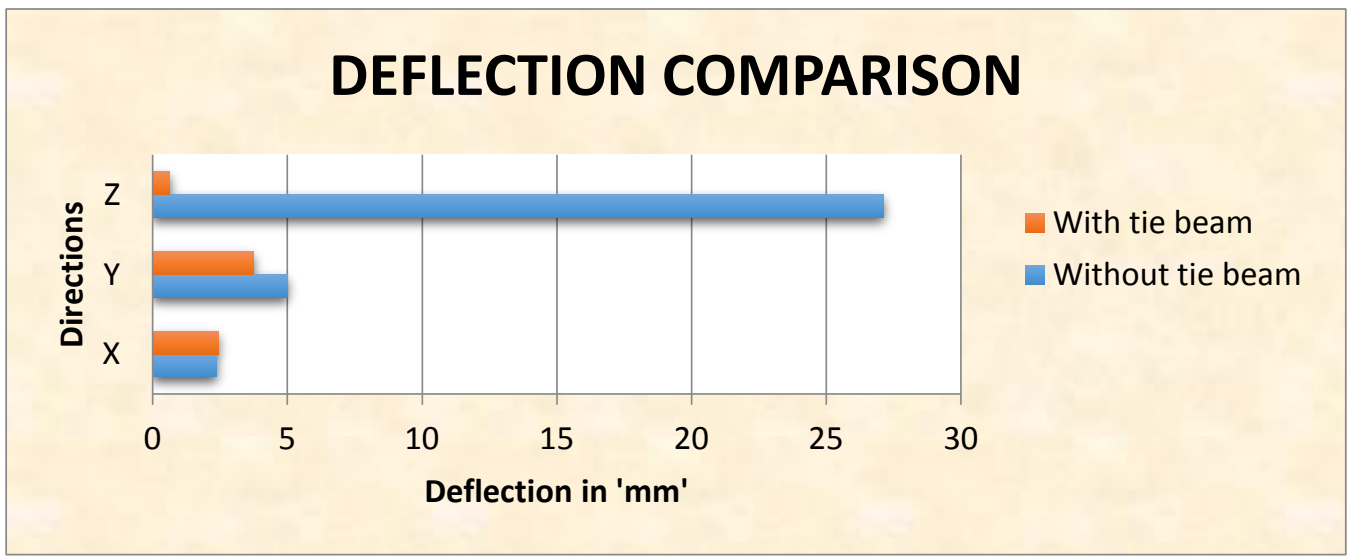

Fig 11. Comparison of deflection of Aqueduct with and without tie beams 


\section{Permissible values:}

As per Cl. 23.2.1 of (IS 456:2000, 2000), permissible value of deflection for simply supported span up to $10 \mathrm{~m}$ span is $20 \mathrm{~mm}$. But for spans exceeding $10 \mathrm{~m}$, the permissible value of deflection is given: $20 \mathrm{x} 10 / \mathrm{span}$ in ' $\mathrm{m}$ '. This gives the permissible deflection value as $20^{*}(10 / 20)=10 \mathrm{~mm}$. As per IS $3370-2009$ (Part 2), the permissible value for bending compressive stress \& direct stress for concrete grade of M-30 is $10 \mathrm{~N} / \mathrm{mm}^{2}$ and $8 \mathrm{~N} / \mathrm{mm}^{2}$ respectively. Fig. 12(a) and Fig. 12(b) show comparison of normal stresses of aqueduct with and without tie beams. It was observed from the results that values of normal stresses for static loads is within permissible limits but the stresses observed for dynamic loads are 2.4 times greater than static loads. For M30 grade of concrete, referring to IS 456:2000, maximum permissible shear stress, $\tau_{c}=3.5$ $\mathrm{N} / \mathrm{mm}^{2}$. If the values are more than permissible, shear reinforcement shall be provided.

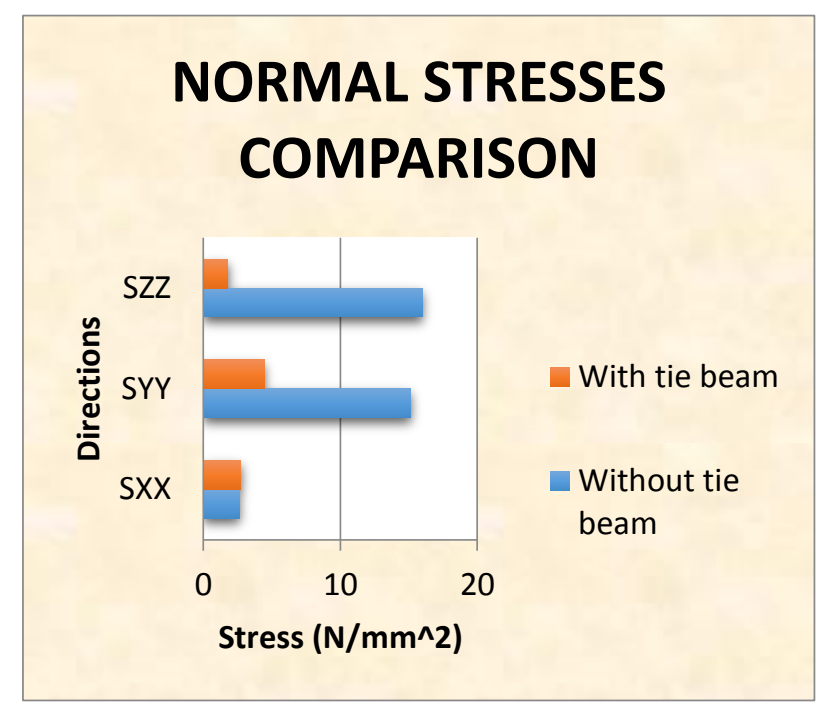

Fig 12. (a) Comparison of Aqueduct with and without tie beams under Normal Stresses

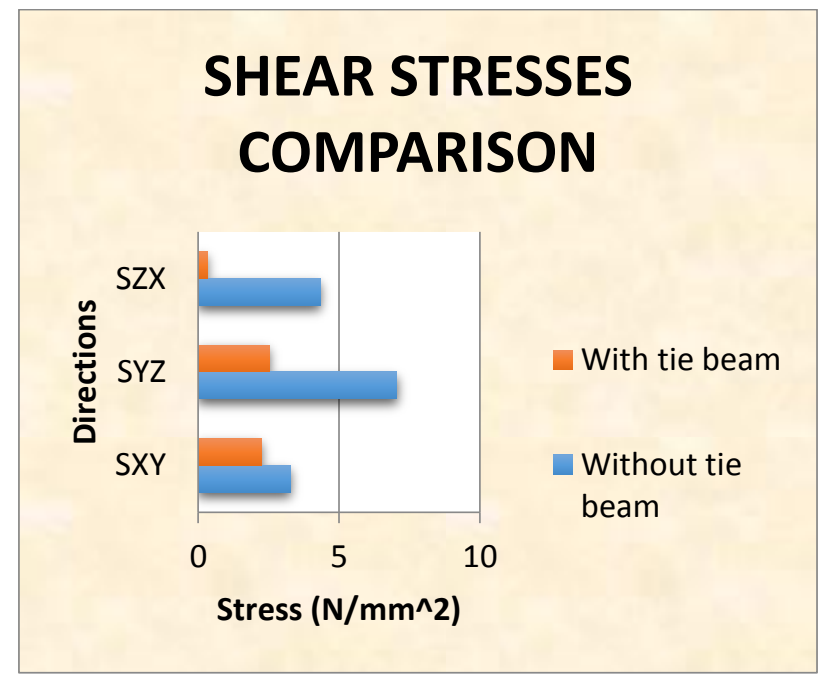

Fig 12. (b) Comparison of Aqueduct with and without tie beams under Normal Stresses

Shear Stress

\subsection{Analysis of Aqueduct with Tie Beams Subjected to both Static and Dynamic Loads}

The results of different parameters for various load criteria of the elements observed in the aqueduct has been divided into left end, mid span and right end for comparison. 


\subsubsection{Displacements}

Fig. 13(a) and 13(b) show the bending behaviour of aqueduct for static and dynamic loads. From the results it has been observed that the displacements due to dynamic loads were about 2.4 times compared to that of the static loads. It can be inferred that, the structures which are safe for carrying static loads might be vulnerable to dynamic loads. So, the effect of water sloshing and the dynamic loads has to be considered for design. The maximum displacements of the aqueduct subjected to static loads and dynamic loads are shown in Fig. 14.

(a)

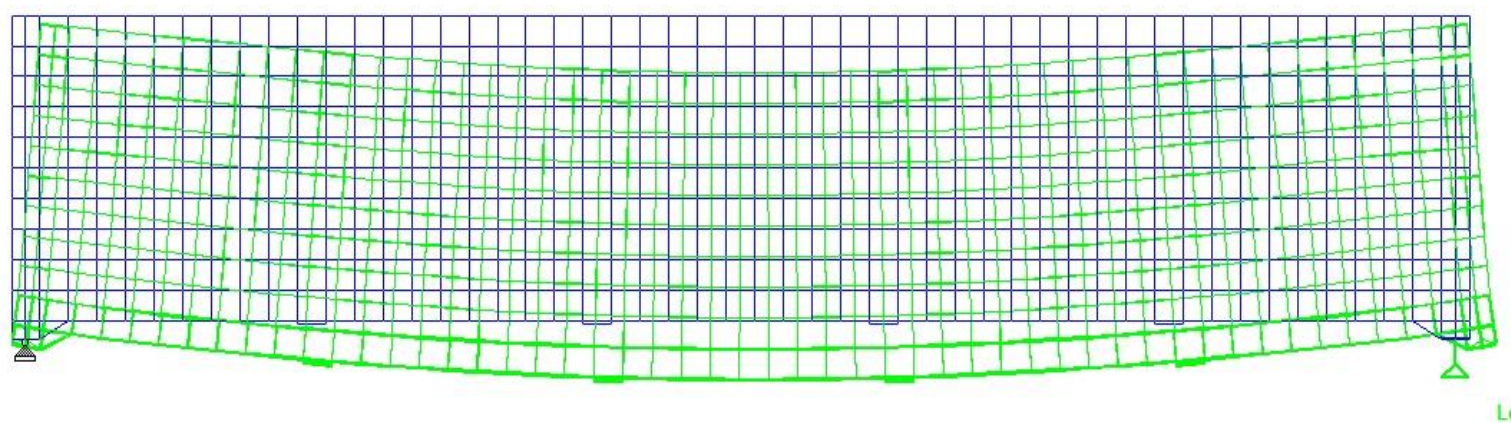

Fig 13. (a) Bending behaviour for static loads

(b)

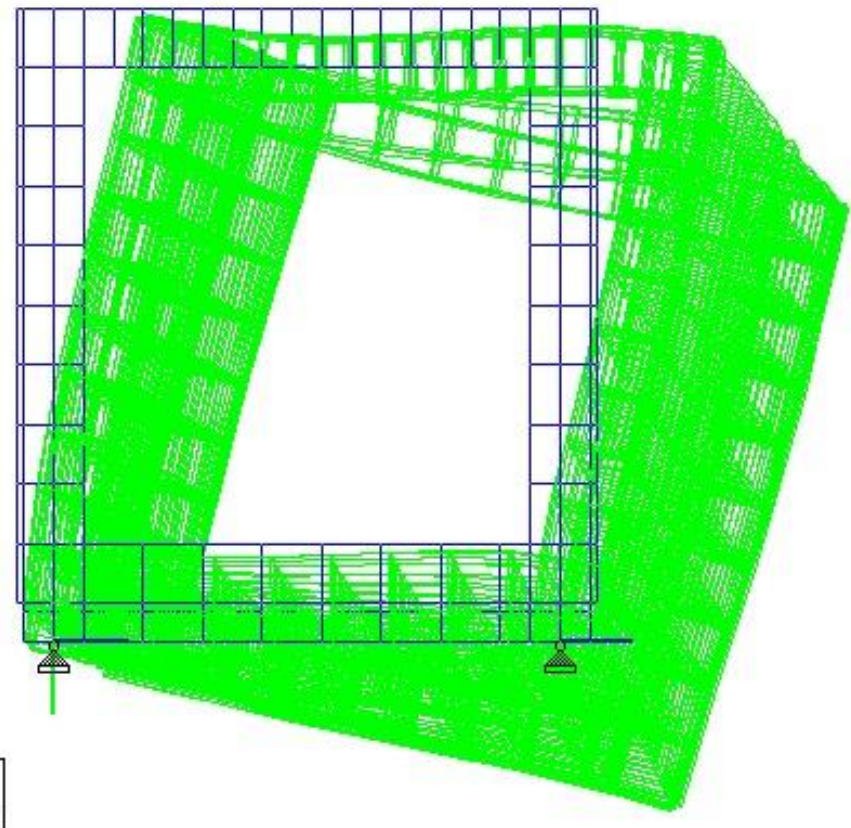

Fig. 13 (b) Bending behaviour for dynamic loads 


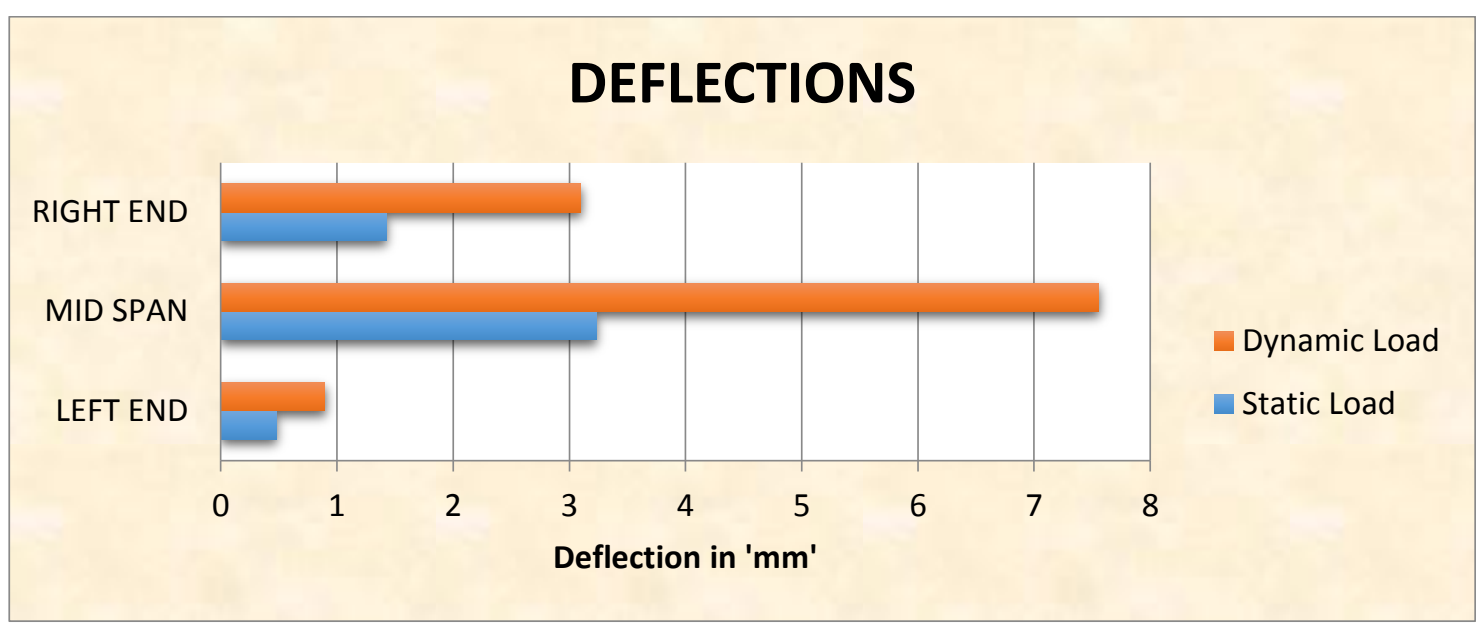

Fig 14. Comparison of deflection of the structure for static \& dynamic loads

\subsubsection{Stresses and its Distribution}

The comparison of normal stresses, shear stresses, and principal stresses on the aqueduct for static and dynamic loading are shown in Fig. 15(a) - 15(c). It was observed in this case as well, the values of shear stress (without shear reinforcement) were in the safe limits for static loads. But for dynamic loads, shear stresses were very large. It is observed that the stresses are maximum at the supporting ends of the aqueduct. But this can be considerably reduced by taking care of necessary base isolation techniques so that the structure is not heavily damaged.

The stress distribution diagrams for hydrostatic loads and hydrodynamic forces under seismic loads have been shown in Fig. 16(a) and Fig. 16(b). The aqueduct structure was found to undergo vertical bending and the stresses were observed to be maximum at the mid span for static loads. The maximum stresses for the hydrodynamic forces were observed to occur at the outer bottom of the aqueduct structure due to the sloshing water. The Stress distribution of tie beams in mid span under static and dynamic loads are shown in Fig. 17(a) and Fig. 17(b), respectively.

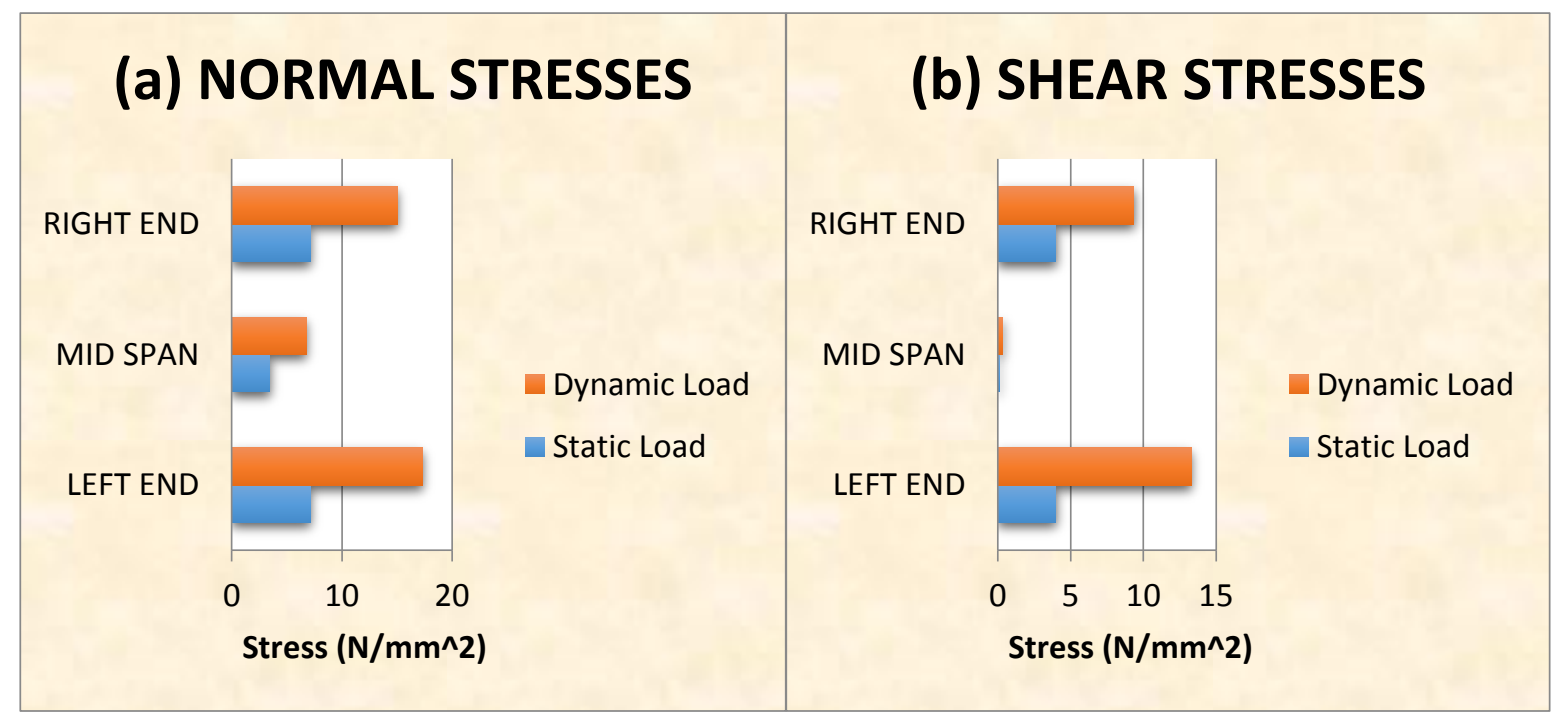




\section{(c) PRINCIPAL STRESSES}

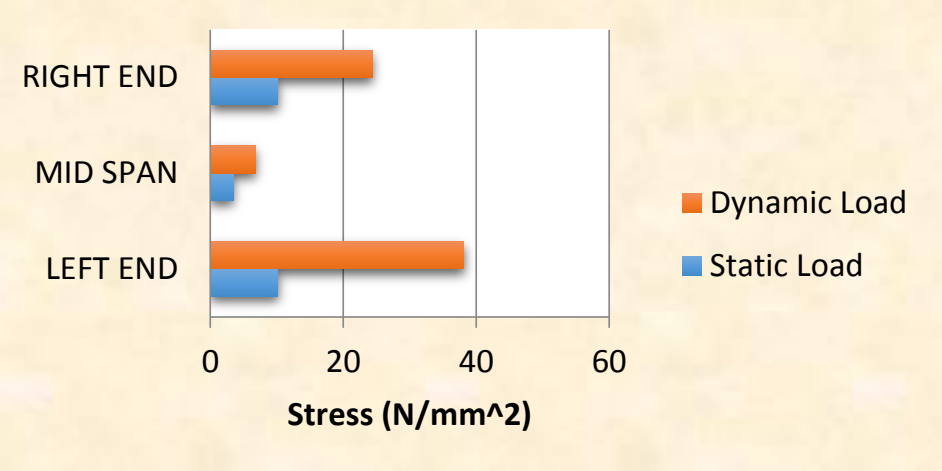

Fig 15. Comparison of (a) Normal stresses (b) Shear stresses (c) Principal stresses
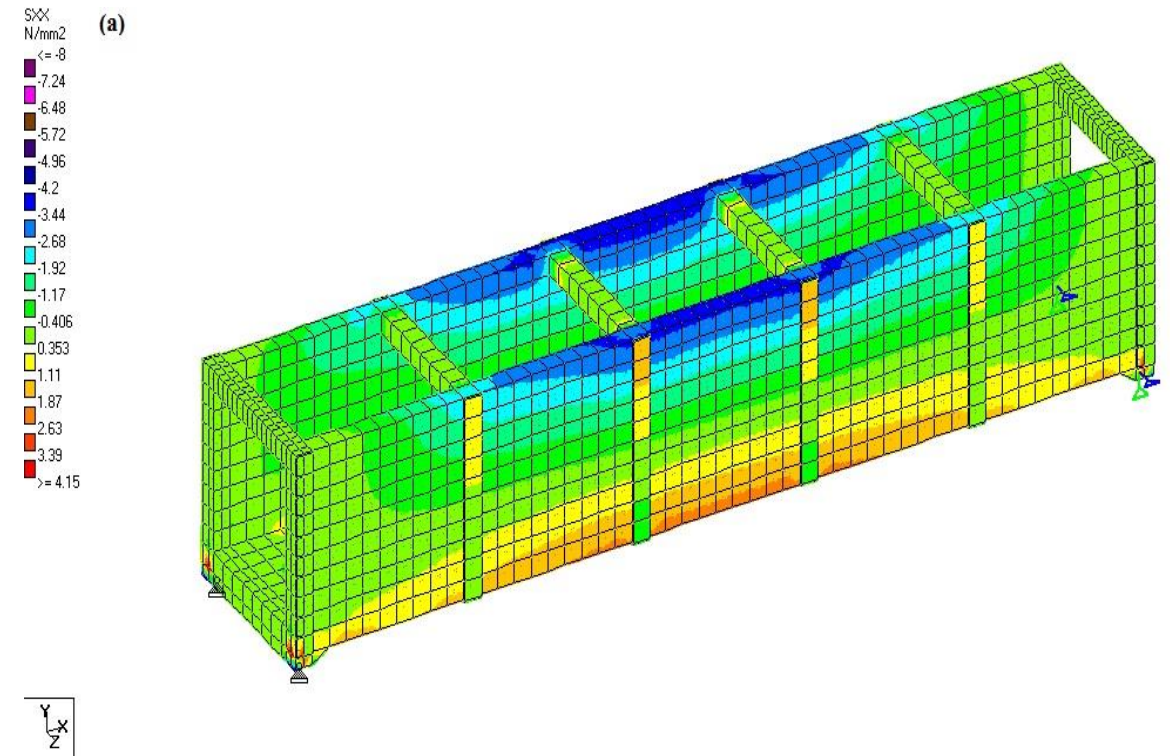

(a)

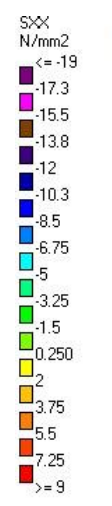

(b)

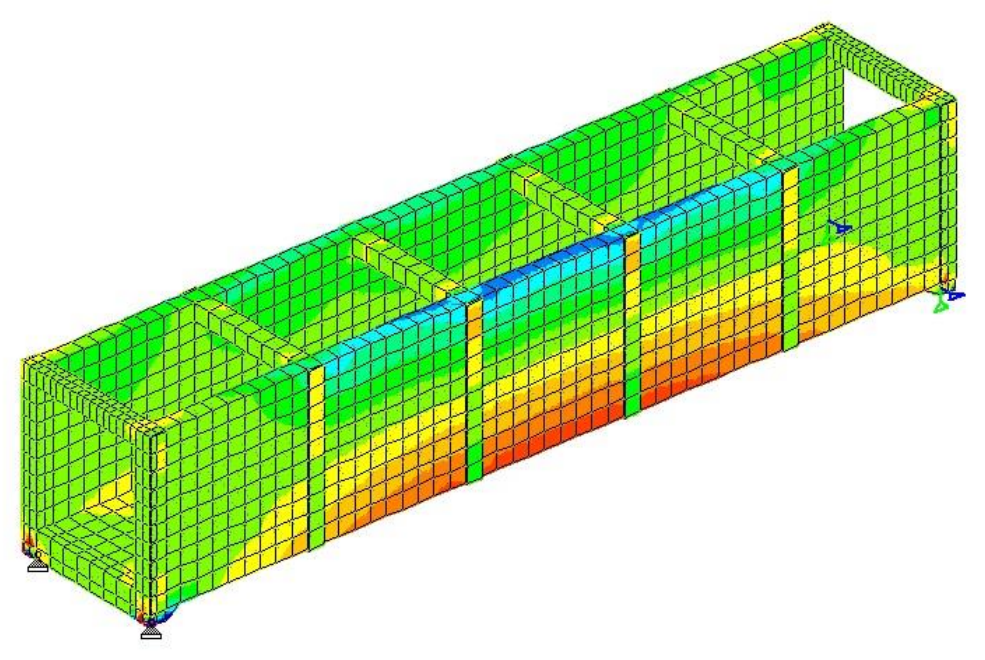

Fig 16. Stress distribution (a) under static loads (b) dynamic loads 


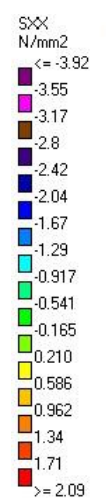

(a)
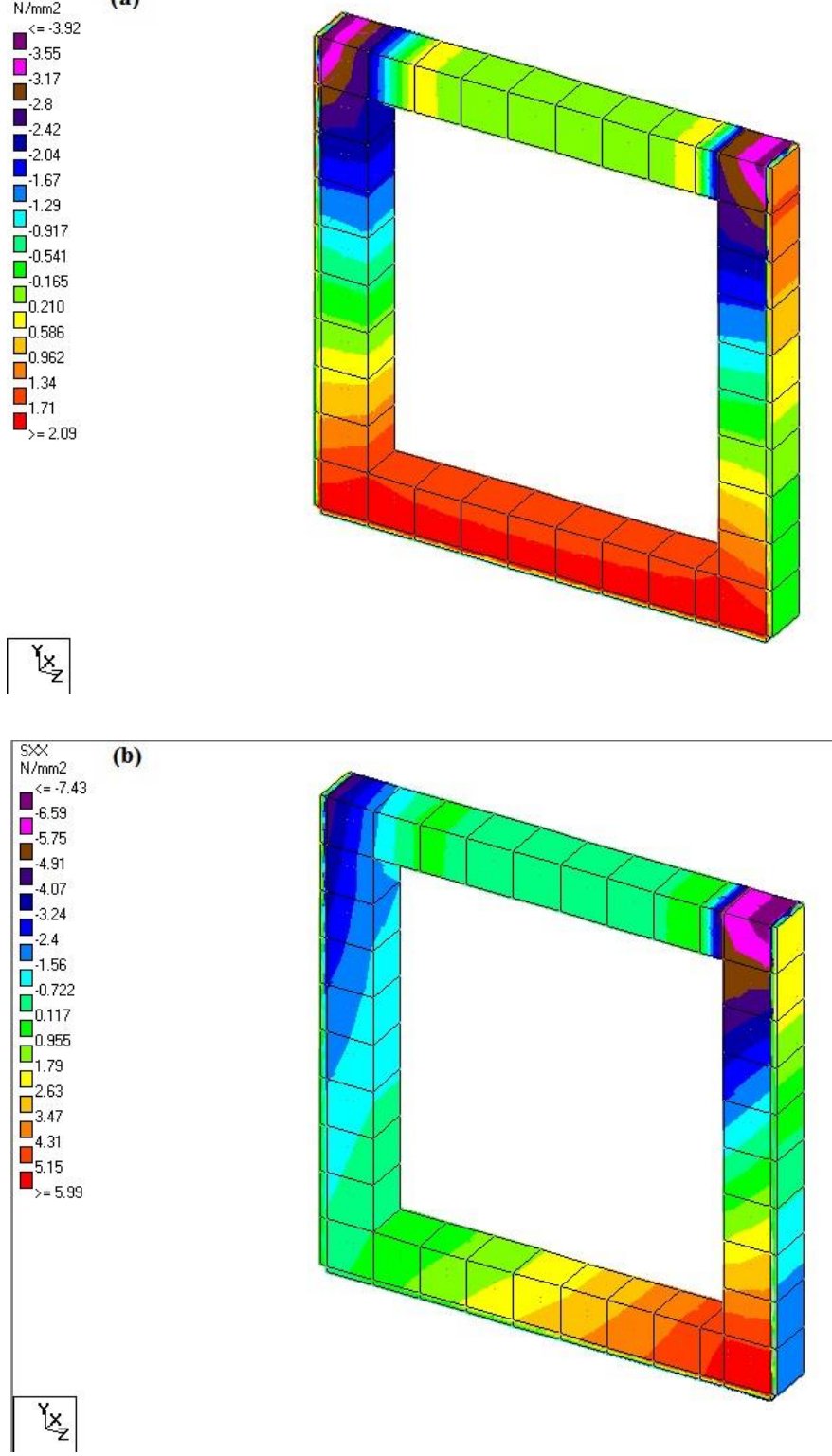

Fig 17. (a) Stress distribution of tie beams in mid span under (a) static loads (b) dynamic loads

\section{Conclusions}

Based upon the analysis the following conclusions are drawn:

- The displacements of the structure in the absence of tie beams at the top is almost 7 times greater than the structure with tie beams under static loads.

- Provision of tie beams at the top proved to be effective in bracing the walls together by reducing the lateral defection significantly.

- The deflections and stresses in the structure due to dynamic Forces is predominant compared to the Static Load. The deflection and stresses developed in the members due to hydrodynamic forces are nearly 2.4 times and 3.8 times more than that due to hydrostatic loads respectively. The deflection is maximum in the mid span and the stresses are maximum at the fixed end of the structure. The maximum stress occurred at the outer bottom of the aqueduct structure caused by the sloshing water and the resulting hydrodynamic forces. 
In this study, elevated aqueduct of single span is modelled and studied. Further the structure can be analyzed taking into consideration of the bearings they are resting upon, design of piers subjected to soil pressure or water pressure depending upon the location of the structure in the seismic zone and the effect of it on the aqueduct. The effect of earthquake motions on the piers and eventually on the aqueduct may be considered. It was observed that the stresses are higher at the ends of aqueduct. So, necessary design of bearings may be done to reduce the effect at the bearing ends of the structure. This can be avoided by using a damping equipment such as isolated bearings to reduce the displacement response in a seismic event. The structure can be made to safely withstand the dynamic forces by ductile detailing of the reinforcements.

\section{References}

Bai, X. L., Fan, Y. Y., Yu, W., \& Wang, D. F. (2011). Dynamic response analysis of large aqueduct structure.In Advanced Materials Research (Trans Tech Publications Ltd). 255, 1159-1162.

Chen, W., \& Hao, H. (2004). Dynamic response analysis of large aqueduct to earthquake ground excitations. In Proc., 13th World Conf. on Earthquake Engineering. Vancouver, BC: Univ. of British Columbia.

Gao, P., Wei, D., Xu, M., \& Li, Z. (2014). Study on the 2.5D Fluid-structure Interaction Model of Beam-type Aqueduct. Journal of Information and Computational Science, 11(13), 4645-4654.

Haroun, M. A., \& Tayel, M. A. (1985).Response of tanks to vertical seismic excitations.Earthquake engineering \& structural dynamics, 13(5), 583-595.

IS 1893 (Part 1): 2016 Criteria for Earthquake Resistant Design of Structures (2016) Bureau of Indian Standards.

IS 3370-2 (2009): Code of Practice Concrete structures for the storage of liquids, Part 2: Reinforced concrete structures (2009).

IS 456:2000 (2000) Plain and Reinforced Concrete Code of Practice, Indian Standard.

Jain, S. K., \&Jaiswal, O. R. (2007).IITK-GSDMA guidelines for seismic design of liquid storage tanks.National Information Centre of Earthquake Engineering, Kanpur.

Li, Y., Lou, M., \& Pan, D. (2003). Evaluation of vertical seismic response for a large-scale beam-supported aqueduct.Earthquake engineering \& structural dynamics, 32(1), 1-14.

Mitra, S., \& Sinhamahapatra, K. P. (2007). Slosh dynamics of liquid-filled containers with submerged components using pressure-based finite element method. Journal of Sound and Vibration, 304(12), 361-381.

Rafiee, A., Vinches, M., \& Bohatier, C. (2008).Modelling and analysis of the Nîmes arena and the Arles aqueduct subjected to a seismic loading, using the Non-Smooth Contact Dynamics method. Engineering Structures, 30(12), 3457-3467.

Salamon, J. W. (2011). Seismic induced loads on spillway gates, phase I - literature review. Tech. Rep. DSO11-06, U.S. Bureau of Reclamation, Denver, Colorado.

Wu, Y., Mo, H. H., \& Yang, C. (2006). Study on dynamic performance of a three-dimensional high frame supported U-shaped aqueduct. Engineering structures, 28(3), 372-380.

Zhang, H., Liu, L., Dong, M., \& Sun, H. (2013). Analysis of wind-induced vibration of fluid-structure interaction system for isolated aqueduct bridge.Engineering structures, 46, 28-37.

Zhang, H., Sun, H., Liu, L., \& Dong, M. (2013). Resonance mechanism of wind-induced isolated aqueductwater coupling system. Engineering structures, 57, 73-86. 